\title{
Fine Structure of Hydrous Chromosomes Observed by Low Vacuum Scanning Electron Microscopy
}

\author{
Keiichi Tanaka ${ }^{1}$, Sumire Inaga ${ }^{2}$, Akihiro IINo $^{2}$, Tatsuo $\mathrm{UShIKI}^{3}$ and Syobu SaIto ${ }^{4}$ \\ Prof. Emer. of Tottori University ${ }^{1}$; Department of Anatomy ${ }^{2}$, Tottori University Faculty of Medicine, Yonago; Department of \\ Anatomy ${ }^{3}$, Niigata University School of Medicine, Niigata; and Hitachi Science Systems Ltd. ${ }^{4}$, Hitachinaka, Japan
}

Received August 25, 1998

\begin{abstract}
Summary. Chinese hamster metaphase chromosomes were stained with platinum $(\mathrm{Pt})$ blue and observed in the hydrous state with low vacuum scanning electron microscopes (LVSEM). The coiled structure of the chromatin fibers in the chromosomes was well recognized through the surrounding perichromosomal substances in the backscattered electron (BSE) mode at accelerating voltages of over $20 \mathrm{kV}$. Findings indicated that chromatin fibers in native chromosomes have a structure similar to the hierarchic coiled model. The present study also demonstrated that not only surface structures but also subsurface structures can be studied in the BSE mode of LVSEM, when the subsurface structures have been stained with heavy metal salts such as Pt blue.
\end{abstract}

More than a century has passed since the spiral structure of chromatin fibers in chromosomes was first observed by BARANETZKY (1880). During this time, a number of techniques have been applied to study the spatial configuration of chromatin fibers, including various kinds of light microscopy, X-ray diffraction, transmission electron microscopy of thin sections or whole mount specimens, scanning electron microscopy (SEM), and atomic force microscopy. Concerning the high-order structure of chromosomes, however, a definite conclusion has not been reached, although several models for the chromosome structure have been proposed to date, such as a multi-strand model (KAUFMANN, 1956; RIS, 1956), folded fiber model (DUPRAW, 1965, 1966) and coiledcoil model (SEDAT and MANUELIDIS, 1978; INAGA et al., 1994).

Recent advances in technology have produced an SEM with a low vacuum specimen chamber which affords the observation of biological specimens in the hydrous state (RoBINSON, 1975). In this study, we observed hydrous chromosomes by use of LVSEM. The aim of the present study is thus to clarify the high-order structure of chromosomes, pursuing our assumption that the chromatin fibers keep their intrinsic arrangement in the hydrous chromosomes in contrast with dried ones.

\section{MATERIALS AND METHODS}

Metaphase chromosomes were isolated from the cultured bone marrow cells of the Chinese hamster using the method of STUBLEFIELD and WRAY (1971). The isolated chromosomes were placed on small pieces of slide glass which were previously treated with $0.1 \%$ poly-L-lysine and fixed with a $1 \%$ paraformaldehyde solution. After rinsing with a buffer solution of $\mathrm{pH} 7.4$, they were stained with a $3 \%$ Pt blue aqueous solution (adjusted to $\mathrm{pH} 9.0$ with $25 \%$ ammonia solution) for 15 min (TANAKA and INAGAKI, 1993). $\mathrm{Pt}$ blue is a general term for a polymeric compound of deep blue in which $\mathrm{Pt}$ is coordinated with amide groups. We used a Pt blue prepared from cisdichlorodiamine-platinum (II) and thymidine, which had a molecular formula of $\left[\mathrm{Pt}_{4}\left(\mathrm{NH}_{3}\right)_{8}\left(\mathrm{C}_{6} \mathrm{H}_{13} \mathrm{O}_{5}\right)_{4}\right]^{+5}$. The specimens were briefly rinsed in distiled water and immersed in $20 \%$ dimethyl sulfoxide solution (DMSO) for $20 \mathrm{~min}$ to avoid ice crystal damage during SEM observation below $0{ }^{\circ} \mathrm{C}$. Specimens thus treated were attached onto a specimen stub with a commercial starch-paste and fitted on the cooling stage of either a Hitachi S-2360 N SEM with a Robinson detector or an S-3200N SEM with a YAG (Yttrium-Aluminum-Garnet) detector. Observations were performed in the BSE mode at $-10^{\circ}$ with a vacuum grade from 90 to $270 \mathrm{~Pa}$; in this condition, chromosomes can be kept in the hydrous state during 

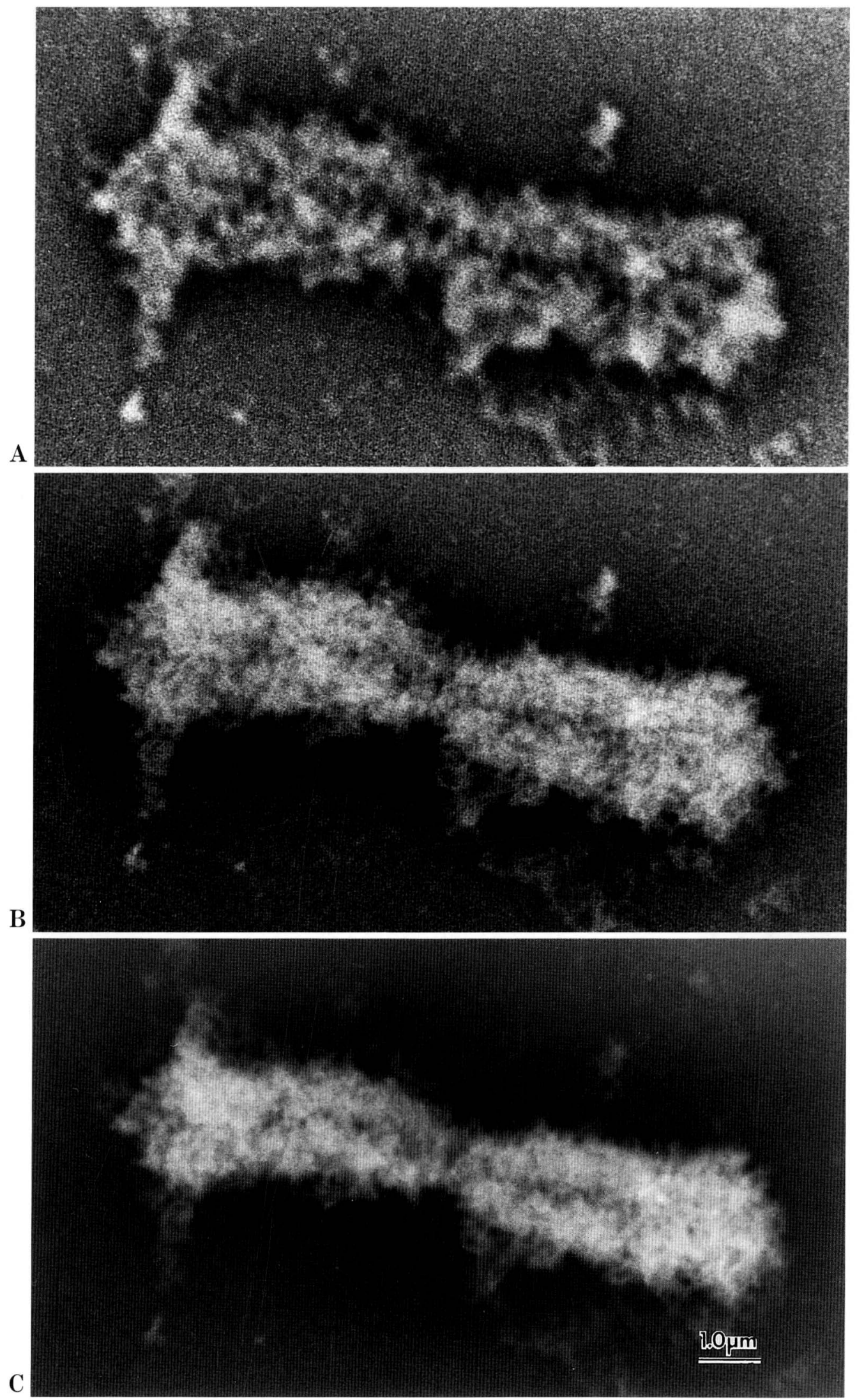

Fig. 1. Legend on the opposite page. 
observations, because the saturated vapor pressure of the water is $270 \mathrm{~Pa}$ at $-10^{\circ} \mathrm{C}$.

\section{RESULTS}

\section{Alteration of BSE images of Pt blue-stained chromosomes by accelerating voltages}

Chromosomes in our specimens consisted of chromatin fibers and their surrounding substances (perichromosomal substances). At an accelerating voltage of $5 \mathrm{kV}$, the surface of the perichromosomal substances was mainly seen (Fig. 1A) because the image was formed from the signals caused by the unevenness of the surface substances (i. e., the surface contrast). At $10 \mathrm{kV}$, the chromatin fibers located under the peri- chromosomal substances appeared in the image together with the surface image of the perichromosomal substances when the atomic number contrast was increased (Fig. 1B). At $20 \mathrm{kV}$, the image of the perichromosomal substances faded away with a decrease in the surface contrast, and only chromatin fibers could be seen in good contrast (Figs. 1C, 2). This was probably due to the very high affinity of the Pt blue for chromatin fibers in contrast with the poorly stained perichromosomal substances. These findings indicated that the BSE images can be changed remarkably according to the accelerating voltage used, and not only the surface structures but also the heavy metal-stained subsurface structures can be selectively observed in this mode.

For these observations, the SEM equipped with a highly sensitive BSE detector of the YAG type was

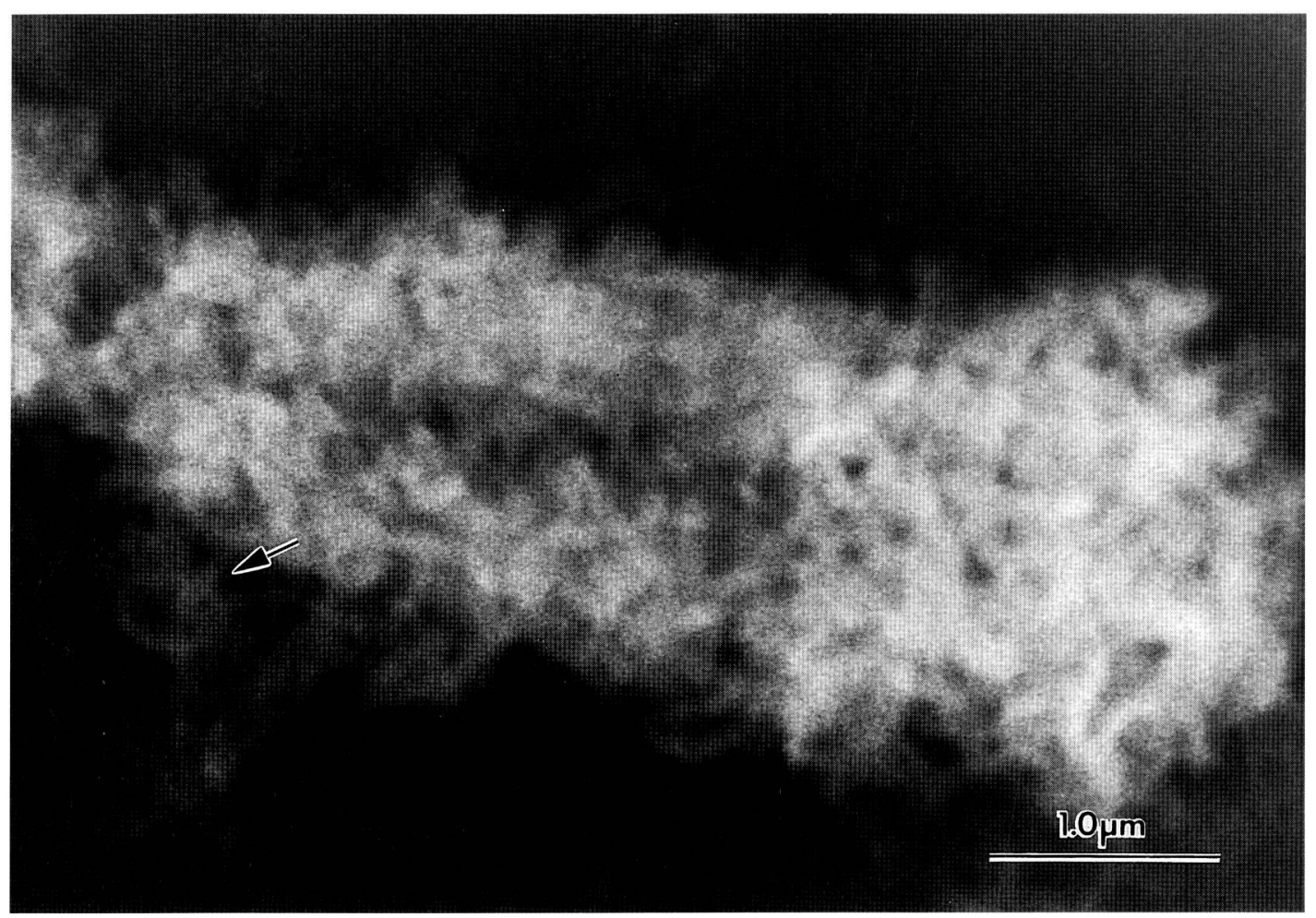

Fig. 2. Enlarged image of the chromosome shown in Figure 1C. Only chromatin fibers are visible. Note a fiber running in a circular fashion (arrow).

Fig. 1. Alteration of SEM: images of a Pt blue-stained chromosome at various accelerating voltages. A. $5 \mathrm{kV}$. The surface of perichromosomal substances is clearly visible, while the chromatin fibers embedded in these substances are obscure. B. $10 \mathrm{kV}$. Chromatin fibers appear in the image together with the perichromosomal substances. C. $20 \mathrm{kV}$. The image of the perichromosomal substances fades away and chromatin fibers can be clearly seen. 


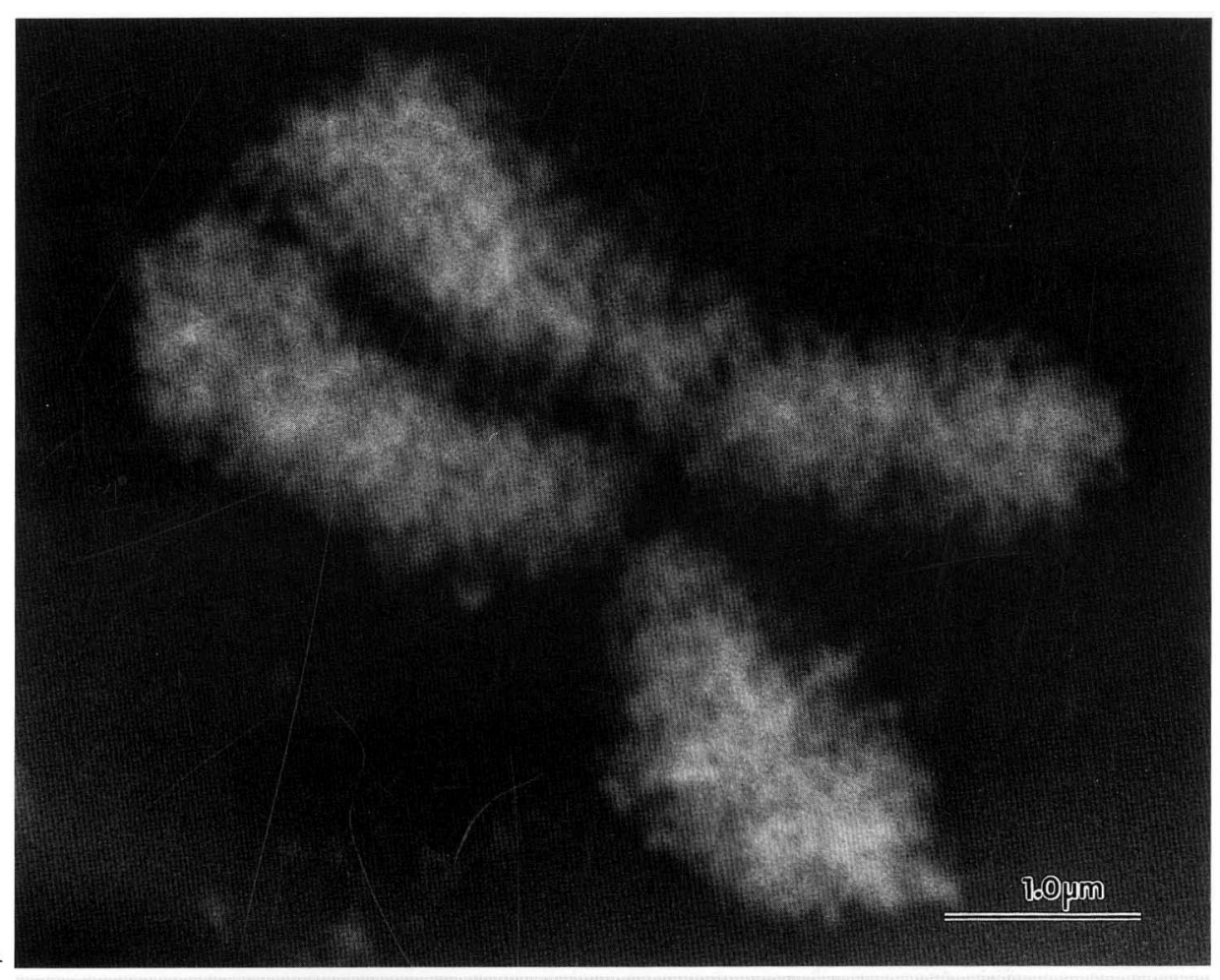

A

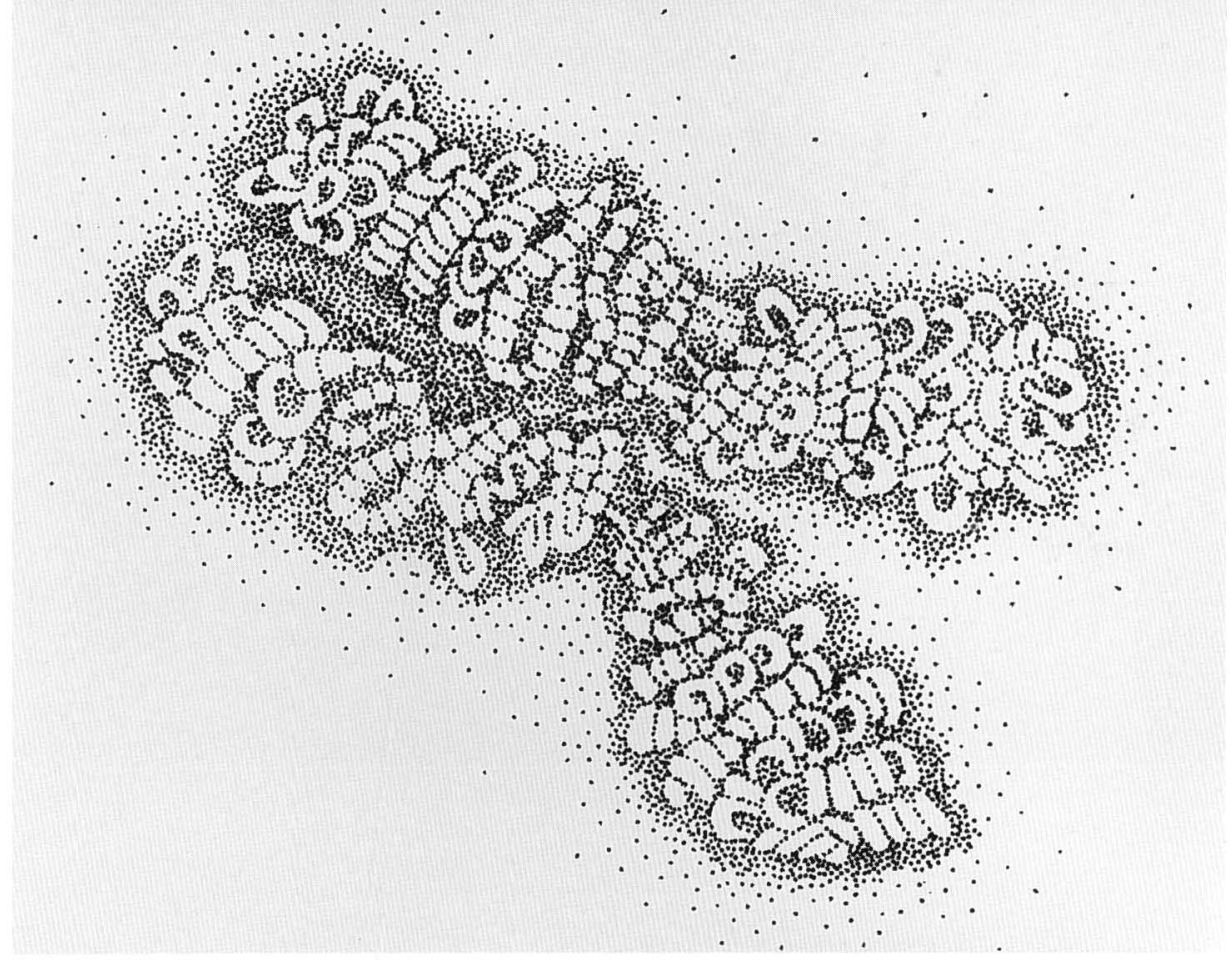

Fig. 3 A. A Pt blue-stained chromosome observed at accelerating voltage of $20 \mathrm{kV}$. The coiled structure of chromatin fibers can be recognized. B. A schematic drawing of a coiled structure of chromatin fibers made by referring to the chromosome image shown in Figure 3A. 
useful, because this SEM had good resolution especially at low accelerating voltages (UsHIKI et al., 1998) as compared with that with a Robinson detector.

\section{Configuration of chromatin fibers in the chromosomes}

Based on the results mentioned above, the spatial configuration of chromatin fibers in the chromosomes was studied. Although some chromosomes were apparently damaged during specimen preparation, in many, the regular arrangement of chromatin fibers in the chromosomes was well-preserved and demonstrated what might be an intrinsic form. The chromosome shown in Figure $3 \mathrm{~A}$ is a good example. Since the direction of the fibers can be recognized fairly well in this micrograph, we made a schematic drawing in reference to the chromosome in Figure $3 \mathrm{~A}$ as is depicted in Figure 3B.

The average diameter of basic chromatin fibers was measured to be roughly $80 \mathrm{~nm}$. The fibers appeared coiled to form thicker threads whose diameters were calculated to be $200-400 \mathrm{~nm}$. Further, the threads seemed to wind up in a rough spiral to make chromatids of a diameter of about $1 \mu \mathrm{m}$.

\section{DISCUSSION}

Since the study by PeAse and HAyes (1966) many researchers have observed chromosomes by conventional SEM methods and reported that chromosomes have coiled or segmental strucures (TANAKA et al., 1970; YAN, 1993; TAKAYAMA and TAKETANI, 1996) However, consensus on the high-order stucure of chromosomes has not been reached, because chromatin fibers in dried chromosomes are usually concealed by the coagulation of adhering perichromosomal substances. It is true that perichromosomal substances can be removed by special treatment (NAGAI et al., 1982). However, the chromatin fibers are artificially irregularly folded after this treatment, even if each fiber can be clearly seen. For examination of the intrinsic arrangement of chromatin fibers, therefore, we should use untreated chromosomes which have been well preserved.

LVSEM, developed about two decades ago, has gradually come to be used in many fields. Although this instrument has several advantages such as affording the observation of non-metal-coated and even hydrous specimens, the maximal useful magnification for observing biological specimens has been limited to approximately $\times 2,000$. Therefore, virtually no researchers of cells and tissues have employed LVSEM in their studies.

In recent years, we have tried to improve the specimen preparation methods and instrumental operation techniques for LVSEM. Through these efforts, we have been able to observe hydrous intracellular structures at a high magnification of $\times 20,000$ and have proven the usefulness of LVSEM for cyto-histology (TANAKA et al., 1997). Among our improved methods, the most important technique for chromosome study is Pt blue staining. As Pt blue has a good affinity for DNA, the chromatin fibers stain very well and can be clearly observed in the dark viewfield of the BSE mode.

Using this technique, alterations of the image of hydrous chromosomes at various accelerating voltages was examined to find the best conditions for research. Consequently, we confirmed that Pt bluestained chromatin fibers can be seen most clearly through the perichromosomal substances at high accelerating voltages of over $20 \mathrm{kV}$. We then analyzed the configuration of chromatin fibers in hydrous chromosomes and found a structure similar to a hierarchic coiling model of chromatin fibers. According to SADAT and MANUELIDIS (1978), and INAGA et al. (1994), the metaphase chromosome hierarchy is composed of several packing orders of fibers composed of at least five levels: 1) nucleosome fibers (10-15 nm thick) showing beads-on a string form; 2) solenoid fibers (20-30 nm thick) in each of which a single nucleosome fiber is folded; 3 ) supercoiled fibers (70 nm thick); 4) coiled chromatid fibers $(250-400 \mathrm{~nm}$ thick); and 5) chromatids (600-1,000 nm thick). The higher order stucture of the chromatin fibers observed in our study may correspond to the third to the fifth level of the coiled-coil model with reference to our previous study concerning chromatin fibers in interphase nuclei (TANAKA and IINO, 1973).

In addition, the diameter of our basic chromatin fibers - of which chromosomes are constructedwas measured and found to be approximately $80 \mathrm{~nm}$. This value was considerably thicker than that reported previously (RIS, 1956; DUPRAW, 1965; WATANABE, 1968; BAHR, 1970). This difference might be mainly due to the water-content in the fibers; we used hydrous specimens, whereas they observed dried specimens.

In this study we further proved that BSE imaging in LVSEM is useful for analyzing not only surface but also subsurface structures, when specimens have been stained with heavy metal salts such as Pt blue. We expect that this observation method will be positively applied for practical use in many fields in the near future. 
Acknowledgements. We would like to express our cordial thanks to Dr. Sukehiro Iтон, Hitachi Science Systems, and Miss. Sayuri MogI, Nissei Sangyo Co., for their helpful assistance.

\section{REFERENCES}

BAHR, G. F.: Human chromosome fibers-Considerations of DNA-protein packing and of looping patterns. Exp. Cell Res. 62: 39-49 (1970).

Baranetzky, J.: Die Kernteilung in den Pollenmutterzellen einiger Tradescantien. Bot. Zeit. 38: 281-296 (1880).

DUPRAW, E. J.: Macromolecular organization of nuclei and chromosomes: A folded fibre model based on whole-mount electron microscope. Nature 206: 338-343 (1965).

-: Evidence for a 'folded-fibre' organization in human chromosomes. Nature 209: 577-581 (1966).

Inaga, S., H. Osatake, T. Katsumoto, T. Kameie, Y. L. YAN, T. NAGURo and A. IINo: Chromatin structure and hierarchy of metaphase chromosome studied by ultrahigh-resolution SEM and TEM. In: (ed. by) D. HERNAN. DEZ-Verdum, J. SChrevel and D. Thomas: Electron microscopy 1994 (Proceedings of 13 th International Congress on Electron Microscopy), vol. 3A. Les e'ditions de physique, Ulis Cedex A, Paris, 1994 (p. 433-434).

Kaufmann, B. P. and N. De DeEPESh: Fine structure of chromosomes. J. Biophys. Biochem. Cytol. 2 (Suppl.) 419-425 (1956).

NAGAI, S., T. InOUE and A. IINo: Fibrous structures of human chromosomes observed by scanning electron microscopy. Cytobios 34: 35-44 (1982).

Pease, R. F. W. and T. L. Hayes: Some biological applications of the scanning electron microscope. In: (ed. by) R. UEDA: Electron microscopy 1966 (Proceeding of 6 th International Congress on Electron Microscopy). Marzen, Tokyo, 1966 (p. 19-20).

RIS, H.: A study of chromosomes with the electron microscope. J. Biophys. Biochem. Cytol. 2 (Suppl. ): 385395 (1956).

Robinson, V. N. E.: A wet stage modification to a scanning electron microscope. J. Microsc. 103: 71-77 (1975).

Sedat, J. and L. Manuelidis: Direct approach to the structure of eukaryotic chromosomes. Cold Spring Harbor Symp. Quant. Biol. 42 (1): 331-350 (1978).

Stublefield, E. and W. Wray: Architecture of the Chinese hamster metaphase chromosome. Chromosoma 32: 262-294 (1971).
Takayama, S. and Y. Taketani: Scanning electron microscopy of novel chromatid configuration induced acid treatment. Chromosome Inform. Service 60: 13-15 (1996).

Tanaka, K. and A. IINo: Demonstration of fibrous components in hepatic interphase nuclei by high resolution scanning electron microscopy. Exp. Cell Res. 81: 40-46 (1973).

TANAKA, K. and K. INAGaKI: Enhancement of the BSE signal from hydrous SEM samples by use of platinum blue. J. Electron Microsc. 42: 255 (1993).

TanaKa, K., S. Inaga and A. IINo: New techniques for observing hydrous biological materials by low vacuum scanning electron microscopy and their applications. In: (ed. by) P. MotTa: Recent advances in microscopy of cells, tissues and organs. Antonio Delfino Editore, Rome, 1997 (p. 31-35).

TANaKa, K., R. Makino and A. IIno: The fine structure of human somatic chromosomes studied by scanning electron microscopy and the replica method. Arch. Histol. Jap. 32: 203-211 (1970).

Ushiki, T., H. Hashizume, S. Ito, K. KuboKi, S. Saito and K. TANaKa: Low-voltage backscattered electron imaging of non-coated biological samples in a lowvacauum environment using a variable-pressure scanning electron microscope with a YAG detector. J. Electron Microsc. 47: 351-354 (1998).

Watanabe, M.: Chromatin fibrils studied by surfacespread electron microscopy. J. Electron Microsc. 17: 243-244 (1968).

YAN, Y-L.: A morphological study on the spiral structure of human mitotic chromosomes. La Kromosomo II-70: 2395-2406 (1993).

\author{
Dr. Keiichi TANAKA \\ IRAGO Institute \\ 337 Ehima-Shinden \\ Atsumi-cho, Atsumi-gun, Aichi \\ 441-3605 Japan \\ 田中 敬一 \\ 441-3605 \\ 愛知県渥美郡渥美町江比間新田 377 \\ いらご研究所 \\ Tel.: +81-5313-7-1680 \\ Fax: +81-5313-4-3111 \\ E-mail: k-tanaka@amitaj.or.jp
}

